\title{
A case of breast carcinoma presenting as carcinoma en cuirasse
}

\author{
İrem Genç ${ }^{1}$, Seray Külcü Çakmak¹, Emine Tamer ${ }^{1}$, Servet Güreşçi², Devrim Tuba Ünal²
}

${ }^{1}$ Department of Dermatology, Ankara Numune Education and Research Hospital, Dermatology Clinic, Ankara, Turkey, ${ }^{2}$ Department of Pathology, Ankara Numune Education and Research Hospital, Pathology Clinic, Ankara, Turkey

Corresponding author: Dr. Seray Külcü Çakmak, E-mail: seraycakmak@gmail.com

\begin{abstract}
Carcinoma en cuirasse is a rare and unique form of cutaneous metastases, which surrounds the trunk in a firm and leathery fibrotic fashion, like an armor. We report a case of carcinoma en cuirasse in a 53 -years-old female patient who was admitted to Dermatology outpatient clinic with pruritic, red, firm papules and plaques on the left breast and arm, extending to upper abdomen and medial part of right breast. At time of admission the patient did not have a history of an internal malignancy. Histopathological diagnosis of the incisional biopsy material from the plaque lesion was consistent with invasive ductal carcinoma. Imaging studies showed axillary, paraaortic, aortocaval lymph node involvement, pleural effusion, lung and liver metastases. The patient was referred to Medical Oncology Department and was treated with cyclophosphamide and adriamycine chemotherapy. This case of carcinoma en cuirasse preceeding the diagnosis of metastatic breast carcinoma and leading to diagnosis of malignancy is rare and important. Prognosis depends on the type of primary tumor and it's biological behavior, predictably, poor prognosis is expected in this case of metastatic invasive ductal carcinoma.
\end{abstract}

Key words: Cutaneous metastases; Carcinoma en cuirasse; Breast carcinoma

\section{INTRODUCTION}

Cutaneous metastases of internal malignities, constitute $2 \%$ of all skin tumors and is important in detecting undiagnosed malignancies and relapses of inadequately treated malignancies [1]. Carcinoma en cuirasse is a rare and unique form of cutaneous metastases, in which the cutaneous metastases cause lymphatic blockage and eventual thickening of chest wall skin, dermal and subcutaneous tissue fibrosis, resulting in armor-like wrapping of the trunk [2]. It generally occurs months to years after the diagnosis of primary cancer. However, rarely it may be the primary symptom of cancer [3].

\section{CASE REPORT}

A 53 -years-old female patient was admitted to Dermatology outpatient clinic with an erythematous rash on trunk and left breast. Patient's history revealed that she had suffered from hardening and shrinking of the left breast for 2 years and it was accompanied by a pruritic rash on trunk and edema in the left arm for the last 3 months. She didn't have any concomitant systemic diseases or use of any drugs.

Dermatological examination revealed distortion of the left areola, contraction and shrinking of the left breast, edema of the left arm and forearm. Dark red and purple colored, infiltrated, semi-firm, non-fading plaque and papules causing peau d'orange appearance was noticed on an area of approximately $50 \times 35 \mathrm{~cm}$ on the left breast extending to the medial aspect of right breast, neck and abdomen (Figs. 1 and 2).

Routine blood tests, tumor markers, breast ultrasonography and mammography were performed. Overall report was BI-RADS-5, recommending tissue sampling from both breasts.

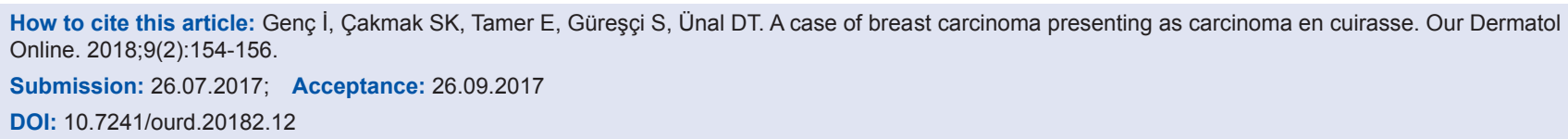


A punch biopsy with the prediagnosis of carcinoma en cuirasse was performed from the lesions on the trunk. It was reported as carcinoma metastasis, tumor cells immunostained with pan CK. Approximately 20\% stained with Estrogen Receptor (ER), 10\% stained with Progesterone Receptor (PR). CerbB2 score was zero. The samples showed no staining with Mammoglobine and GCDFP15. These findings were consistent with breast cancer metastasis (Figs. 3-7). Incisional biopsy material from both breasts were consistent with invasive ductal carcinoma.

Bilateral enlarged axillary lymph nodes, pleural effusion and adjacent collapsed lung areas were detected in thorax and abdominal computed tomography. Multiple nodules were present in bilateral lungs. Multiple mass lesions showing contrast retention compatible with metastases were visualised in liver. Paraaortic and aortocaval lymph nodes were present.

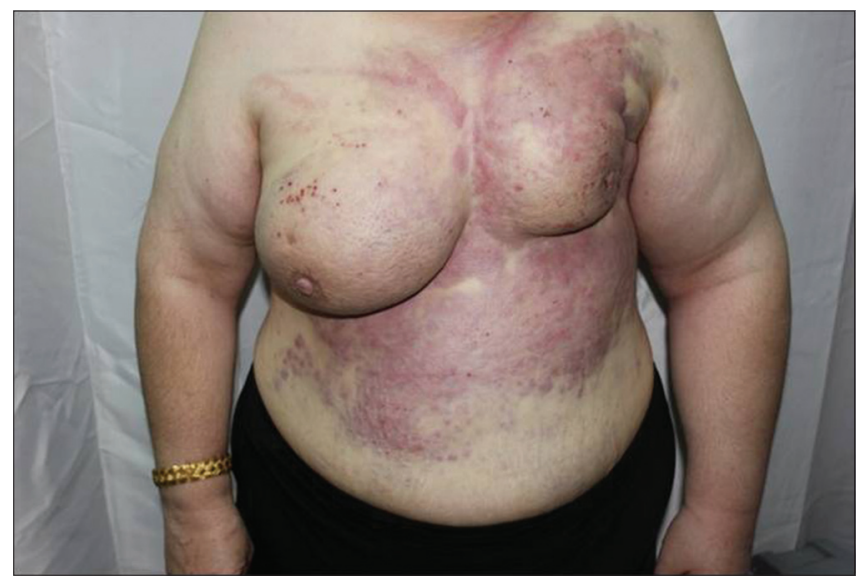

Figure 1: Infiltrated, plaque and papules causing peau d'orange appearance on the left breast extending to the medial aspect of right breast, neck and abdomen.

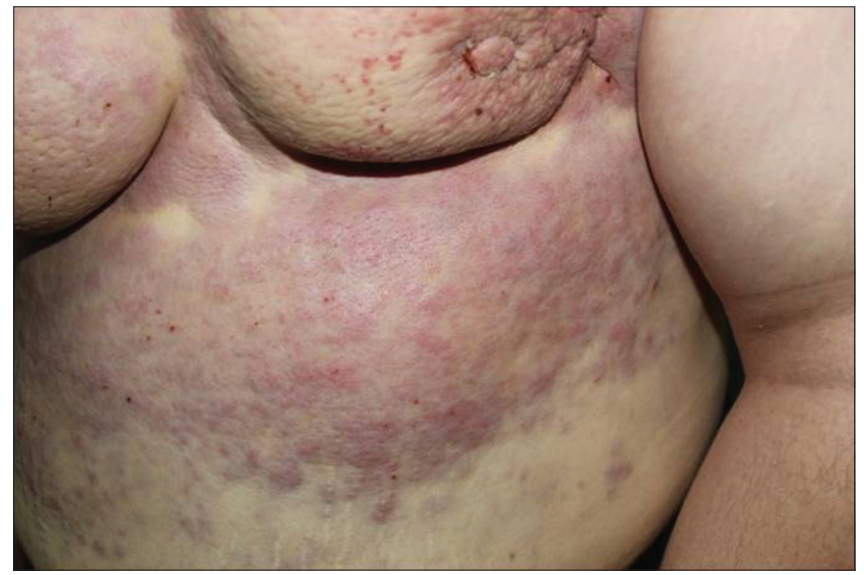

Figure 2: Close up image revealing infiltrated erythematous plaque and papules.
Patient was referred to Medical Oncology Department and chemotherapy with the diagosis of metastatic invasive ductal carcinoma was initiated.

\section{DISCUSSION}

Cutaneous metastases of internal malignities are relatively rare encountered conditions and of diagnostic importance for undiagnosed malignancies [3]. In female patients, most frequently breast cancer (69\%), colon cancer $(6 \%)$, melanoma $(5 \%)$ and cervix cancers (2\%) were accused of this condition [4].

Cutaneous breast cancer metastases can be seen in different morphological patterns such as papulonodular lesions, erysipeloid or sclerodermoid infiltrations [5]. Carcinoma en cuirasse is a special fibrotic form of cutaneous metastases, spreading rapidly and wrapping the trunk like a leather armor [6]. Lymphatic drainage

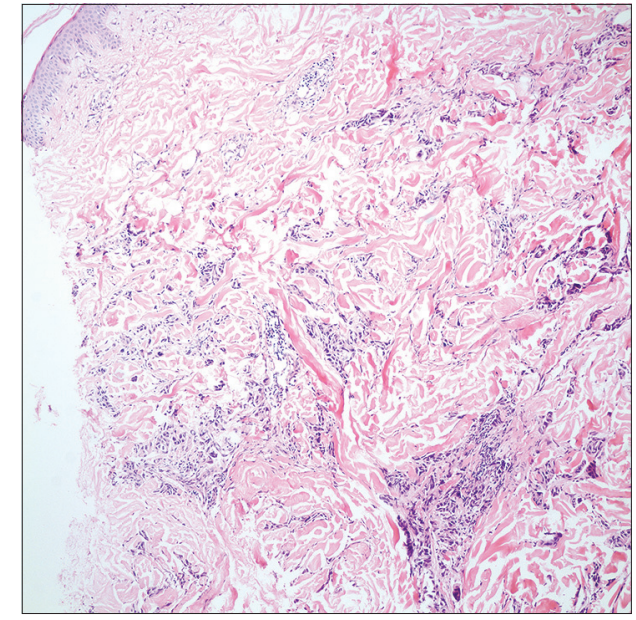

Figure 3: Infiltration of tumoral cells in dermis (HE x10).

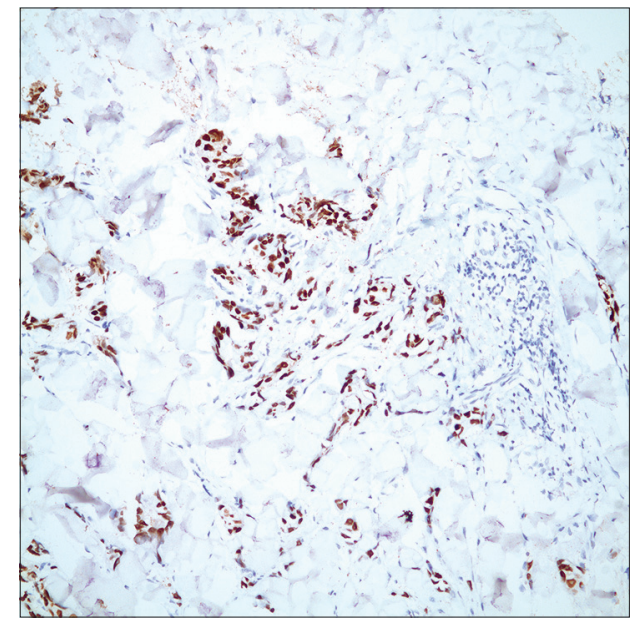

Figure 4: Tumour cells showing cytoplasmic staining with pan cytokeratin antibody (IHK x20). 


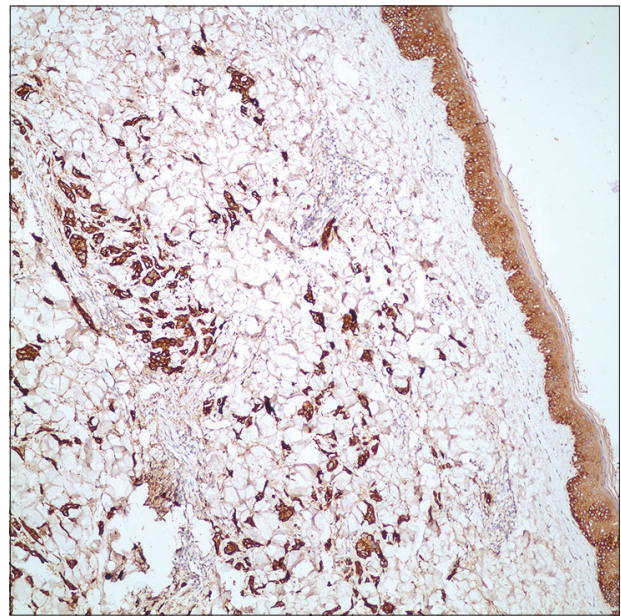

Figure 5: Tumour cells showing nuclear staining with estrogen receptor (IHK x20).

is disturbed, causing thickening of chest wall skin and edema, eventually resulting in fibrosis of the dermis and subcutaneous tissue [2]. This situation causes lymphedema, pitting of the skin and peau d'orange appearance $[4,5]$. Duration from cancer diagnosis to cutaneous metastasis may differ, however, generally it's seen in 3 years following the diagnosis [5]. Rarely, in some patients cutaneous metastases may be seen as the first and/or only symptom of the malignancies [3].

\section{CONCLUSION}

This patient is worth presenting due to carcinoma en cuirasse along with breast distortion and areola retraction being the preceding symptom of breast cancer. In this case, recognizing the cutaneous metastasis was important for initiation of the treatment and preventing further metastasis.

\section{REFERENCES}

1. Alcaraz I, Cerroni L, Rütten A, Kutzner H, Requena L. Cutaneous metastases from internal malignancies: A clinicopathologic and immunohistochemical review. Am J Dermatopathol. 2012;34:347-93.

2. Bhat R, Khaitan BK, authors; Valia RG, Valia AR, editors. Skin manifestations in internal diseases. IADVL Textbook of Dermatology. 2008. $3^{\text {rd }}$ ed. Mumbai: Bhilani Publishing House; p. 1347-409.

3. Mahore SD, Bothale KA, Patrikar AD, Joshi AM. Carcinoma en cuirasse: A rare presentation of breast cancer. Indian J Pathol Microbiol. 2010;53:351-8.

4. Cutaneous metastases and paget's disease of the skin. In: McKee PH, Calonje E, Granter SR, editors. Pathology of the skin with clinical correlations. $3^{\text {rd }}$ ed. Philadelphia, USA: Elsevier: Mosby; 2005.p.1497-518.

5. JohnsonWC. Metastatic carcinoma of the skin, Incidence and dissemination. In: Elder D, Elenitsas R, Jaworsky C, Johnson B, editors. Lever' Histopathology of the skin. $8^{\text {th }}$ ed. Philadelphia: Lippincott Williams e Wilkins; 1997. pp. 1011-1018.

6. Vano-Galvan S, Moreno-Martin P, Salguero I, Jaen P. Cutaneous metastases of breast carcinoma: A case report. Cases J. 2009;2:71.

Copyright by İrem Genç, et al. This is an open-access article distributed under the terms of the Creative Commons Attribution License, which permits unrestricted use, distribution, and reproduction in any medium, provided the original author and source are credited.

Source of Support: Nil, Conflict of Interest: None declared. 